\title{
Análise de fases por difração de raios $X$ de WC-10\%Co dopado com terras-raras obtido sob alta pressão
}

\author{
Phase analysis by x-ray diffraction on the WC-10Co \\ doped with rare-earth elements obtained under high \\ pressure
}

Grupo de Materiais Cerâmicos - LAMAV-CCT/UENF.

Av. Alberto Lamego 2000, Campos dos Goytacazes, RJ. CEP: 28013-602.

e-mail: cristianefmarques@gmail.com ; guerold@uenf.br ; holanda@uenf.br

\section{RESUMO}

O carbeto cementado WC-Co também denominado de metal duro é um material de grande importância tecnológica produzido por metalurgia do pó através de sinterização por fase líquida, partindo-se da mistura dos pós de carbeto de tungstênio (WC) e de cobalto (Co) em moinho convencional. Entretanto, para obtenção de metal duro com maior capacidade (produtividade, vida útil, etc.), uma nova rota alternativa de metalurgia do pó denominada de altas pressões e altas temperaturas vem sendo utilizada para produção destes materiais com resultados promissores. O presente trabalho tem como objetivo principal a análise de fases de WC-10Co dopado com terras-raras $\left(\mathrm{La}_{2} \mathrm{O}_{3}, \mathrm{CeO}_{2} \mathrm{e} \mathrm{Y}_{2} \mathrm{O}_{3}\right)$ preparadas sob condições de alta pressão. Esta liga de metal duro é um exemplo de material compósito largamente utilizado como ferramenta de corte e operações de usinagem em geral. Foram preparadas diversas misturas de WC-10Co contendo até $2 \%$ em peso de terra-rara $\left(\mathrm{La}_{2} \mathrm{O}_{3}, \mathrm{CeO}_{2} \mathrm{e} \mathrm{Y}_{2} \mathrm{O}_{3}\right)$ da fase cobalto. Os pós previamente misturados foram compactados numa matriz cilíndrica $(\phi=7 \mathrm{~mm})$ a uma pressão de $800 \mathrm{MPa}$ e sinterizados a $1400^{\circ} \mathrm{C}$ durante $40 \mathrm{~s}$ sob alta pressão de 5,5 GPa. Os compósitos produzidos foram caracterizados por difração de raios X para identificação de fases cristalinas presentes. Além disso, foi feita análise comparativa entre o carbeto isento de terra-rara (amostras de referência) e carbetos dopados com elementos de terra-rara $\left(\mathrm{La}_{2} \mathrm{O}_{3}, \mathrm{CeO}_{2}\right.$, e $\left.\mathrm{Y}_{2} \mathrm{O}_{3}\right)$. Para as condições estudadas os resultados mostraram que durante o processo de sinterização ocorreu à formação, mesmo que em pequenas quantidades, das fases $\mathrm{Co}_{3} \mathrm{~W}_{3} \mathrm{C}$ e $\gamma$ (carbeto tipo $\varepsilon$ ) nas peças de metal duro estudadas.

Palavras chaves: metal duro, terra-rara, alta pressão, difração de raios X.

\section{ABSTRACT}

The WC-Co cemented carbide also called hardmetal is a material of great technological importance, currently produced by powder metallurgy by liquid phase sintering, starting from the mixture of powdered tungsten carbide (WC) and cobalt (Co) using conventional mill. Seeking to obtain materials with higher capacity (productivity, life, etc.), an alternative route for powder metallurgy called High Pressure High Temperature (HPHT) has been used for the production of these materials with promising results. The main aim of this work is the phases analysis of the WC-10Co doped with rare-earths $\left(\mathrm{La}_{2} \mathrm{O}_{3}, \mathrm{CeO}_{2}\right.$, and $\left.\mathrm{Y}_{2} \mathrm{O}_{3}\right)$ obtained under high pressure. This hardmetal alloy is an example of the composite material widely used as cutting tool and machining processes in general. Several WC-10Co mixtures containing up to 2 wt $\% \mathrm{La}_{2} \mathrm{O}_{3}, \mathrm{CeO}_{2}$ and $\mathrm{Y}_{2} \mathrm{O}_{3}$ of the cobalt phase were prepared. The mixed powders were pressed at $800 \mathrm{MPa}$ in a cylindrical matrix $(\phi=7 \mathrm{~mm})$ and sintered at $1400^{\circ} \mathrm{C}$ during $40 \mathrm{~s}$ under high pressure (5.5 GPa). The identification of the crystalline phases was done by X-ray diffraction. In addition, comparative analysis between the free rareearth and doped with rare-earths elements $\left(\mathrm{La}_{2} \mathrm{O}_{3}, \mathrm{CeO}_{2}\right.$ and $\left.\mathrm{Y}_{2} \mathrm{O}_{3}\right)$ carbides was done. The results showed that, within the conditions studied during the sintering process, formation, even, small amounts, of the phases $\mathrm{Co}_{3} \mathrm{~W}_{3} \mathrm{C}$ and $\gamma$ ( $\varepsilon$ carbide type) were observed in the carbide pieces studied.

Keywords: Hardmetal, rare-earth, high pressure, XRD. 


\section{INTRODUÇÃo}

Os carbetos cementados consistem de um carbeto refratário de alta dureza embebido numa matriz tenaz denominada metal ligante. As propriedades do metal duro dependem da combinação das propriedades de seus constituintes, que são manipulados de tal forma a obter as características requeridas. A melhor combinação destas propriedades é fornecida pelo WC-Co, sendo 90 \% de WC e 10\% de Co a composição mais usual [1]. Estes materiais têm sido extremamente utilizados, principalmente, na indústria metalúrgica e petrolífera como, por exemplo, ferramentas de corte de materiais ferrosos e não-ferrosos e operações de usinagem em geral.

Os carbetos cementados são fabricados via processos convencionais da Metalurgia do Pó tais como: compactação/sinterização, prensagem a quente e sinter/HIP [2-6]. Entretanto, uma nova rota conhecida como HPHT- altas pressões e altas temperaturas, onde a sinterização ocorre a intervalos de tempos muito curtos, tem sido utilizada no processamento de WC-Co [7-8] visando obter propriedades superiores aos dos processos convencionais.

Nos últimos anos, pesquisas têm sido voltadas para o entendimento da influência das terras-raras sobre o processo de sinterização de carbetos cementados e suas propriedades. As razões para isto devem-se aos possíveis efeitos benéficos como, por exemplo, diminuição do tamanho de grão do WC na estrutura, diminuição da porosidade, aumento da dureza, aumento da resistência mecânica, aumento da resistência ao desgaste e melhor desempenho de corte que os elementos de terra-rara podem causar nos carbetos cementados [9-11].

No presente trabalho foi produzido o carbeto cementado WC-10\%Co, dopado com diferentes elementos de terras-raras $\left(\mathrm{La}_{2} \mathrm{O}_{3}, \mathrm{CeO}_{2}\right.$ e $\left.\mathrm{Y}_{2} \mathrm{O}_{3}\right)$, sob condições de alta pressão e alta temperatura. Ênfase especial foi dada à análise por difração de raios $\mathrm{X}$ ao efeito da adição de terras-raras sobre a estrutura das peças de metal duro.

\section{MATERIAIS E MÉTODOS}

Neste trabalho foram preparadas treze amostras do carbeto cementado, WC-10\%Co, com adições de até $2 \%$ em peso de terras-raras $\left(\mathrm{La}_{2} \mathrm{O}_{3}, \mathrm{CeO}_{2}\right.$ e $\left.\mathrm{Y}_{2} \mathrm{O}_{3}\right)$ da fase cobalto, conforme mostrado na Tabela 1. O pó de carbeto de tungstênio (WC) com tamanho de partícula médio de $0,98 \mu \mathrm{m}$, apropriado para produção industrial de carbeto cementado, foi fornecido pela WolframBergbau-Und-GmbH (Áustria). Os pós de cobalto (Co) com tamanho de partícula $<37 \mu \mathrm{m}$, apropriado para produção de carbeto cementado, óxido de lantânio $\left(\mathrm{La}_{2} \mathrm{O}_{3}\right)$ com 99,99 \% de pureza e óxido de cério $\left(\mathrm{CeO}_{2}\right)$ com 99 \% de pureza foram fornecidos pela VETEC Química Fina. O pó de óxido de ítrio $\left(\mathrm{Y}_{2} \mathrm{O}_{3}\right)$ com pureza de 99,99 \% foi fornecido pela SIGMAAldrich.

Tabela 1: Composição das misturas sem e com terras-raras (\% em peso).

\begin{tabular}{|c|c|c|c|c|}
\hline \multirow[b]{2}{*}{ AMOSTRAS } & \multirow[b]{2}{*}{ WC/10Co } & \multicolumn{3}{|c|}{ TERRA-RARA } \\
\hline & & $\mathrm{La}_{2} \mathrm{O}_{3}$ & $\mathrm{CeO}_{2}$ & $\mathrm{Y}_{2} \mathrm{O}_{3}$ \\
\hline Am0 & 100,0 & 0,0 & 0,0 & 0,0 \\
\hline Am1 & 99,5 & 0,5 & ---- & ---- \\
\hline Am2 & 99,0 & 1,0 & ---- & ---- \\
\hline Am3 & 98,5 & 1,5 & ---- & ---- \\
\hline Am4 & 98,0 & 2,0 & ---- & ---- \\
\hline Am5 & 99,5 & ---- & 0,5 & ---- \\
\hline Am6 & 99,0 & ---- & 1,0 & ---- \\
\hline Am7 & 98,5 & ---- & 1,5 & ---- \\
\hline
\end{tabular}




\begin{tabular}{|c|c|c|c|c|}
\hline \multirow[b]{2}{*}{ AMOSTRAS } & \multirow[b]{2}{*}{ WC/10co } & \multicolumn{3}{|c|}{ TERRA-RARA } \\
\hline & & $\mathrm{La}_{2} \mathrm{O}_{3}$ & $\mathrm{CeO}_{2}$ & $\mathrm{Y}_{2} \mathrm{O}_{3}$ \\
\hline Am8 & 98,0 & ---- & 2,0 & $\mid---$ \\
\hline Am9 & 99,5 & ---- & ---- & 0,5 \\
\hline Am10 & 99,0 & ---- & ---- & 1,0 \\
\hline Am11 & 98,5 & ---- & ---- & 1,5 \\
\hline Am12 & 98,0 & ---- & ---- & 2,0 \\
\hline
\end{tabular}

O processo de mistura dos pós (90\%pesoWC10\%pesoCo + X\%pesoterras-raras) foi realizado em um misturador de laboratório durante $1 \mathrm{~h}$. Após mistura, os pós foram pré-compactados por prensagem uniaxial a pressão de $800 \mathrm{MPa}$, utilizando-se uma matriz cilíndrica ( $\phi=7 \mathrm{~mm})$.

Os compactos obtidos foram colocados dentro de uma cápsula deformável de calcita, a qual é responsável pela formação da gaxeta e garante a distribuição homogênea da alta pressão nas amostras. Para uma condução de calor efetiva nas amostras, a cápsula foi coberta com uma tampa cilíndrica composta de $50 \%$ de grafite e $50 \%$ de calcita preparadas por compactação a $800 \mathrm{MPa}$. As amostras foram sinterizadas sob condições de alta pressão $(5,5 \mathrm{GPa})$ e alta temperatura $\left(1400^{\circ} \mathrm{C}\right)$ durante $40 \mathrm{~s}$ numa prensa especial (marca Ryazantyashpressmash, modelo DO 138B, 630 ton.) usando um dispositivo de alta pressão [12].

As amostras de carbeto, obtidas, foram submetidas à análise por difração de raios $\mathrm{X}$ num difratômetro convencional (marca Shimadzu, modelo DRX 7000), utilizando-se radiação $\mathrm{Cu}-\mathrm{K} \alpha$, intervalo angular (20): 20-90, velocidade angular (deg/min): 0,05 e tempo de permanência em ângulo (s): 1. A análise qualitativa das fases cristalinas presentes foi efetuada através da comparação do ângulo de difração de Bragg, distância interplanar e da intensidade relativa dos principais picos, com as fichas padrão JCPDS 73-0471, 15-0806, 060639, 01-0640 e 27-1125.

\section{RESULTADOS E DISCUSSÃO}

Nas Figuras 1-13 são apresentados os difratogramas de raios X obtidos para o compósito, WC-10Co, dopado com até $2 \%$ em peso de diferentes elementos de terra-rara. Para melhor compreensão foram analisadas as amostras antes e após sinterização sob condições de alta pressão e alta temperatura.

A Figura 1 apresenta os difratogramas de raios X obtidos para a amostra Am0 (WC-10\%Co) na condição isenta de terra-rara. Na Figura 1(a) que corresponde à amostra na temperatura ambiente, antes da sinterização, foram identificados os picos referentes às fases cristalinas WC e Co. Nota-se, também, a dificuldade na identificação dos picos de Co. Isto pode estar relacionado à sua baixa intensidade ao contrário dos picos de WC que são bem intensos. Este comportamento já era esperado uma vez que a mistura padrão estudada corresponde a $10 \%$ de Co e $90 \%$ de WC. Além disso, é possível ainda estar relacionado à radiação $\mathrm{Cu}-\mathrm{K} \alpha$ utilizada, que provavelmente foi absorvida pelo cobalto. A baixa intensidade dos picos de cobalto foi observada em todas as amostras de acordo com as Figuras 2-13, independente do teor de terra-rara adicionado. Observa-se, ainda, o aparecimento de um pequeno pico em aproximadamente $2 \theta=25,76^{\circ} \mathrm{em}$ todos os difratogramas antes da sinterização. Este pico provavelmente está relacionado ao carbono, em forma de grafite, contido no pó de WC utilizado.

Na Figura 1(b) é apresentado o difratograma de raios X da amostra Am0 sinterizada sob condições de alta pressão e alta temperatura. Pode-se observar que durante a sinterização ocorreu a formação, mesmo que com picos de baixa de intensidade, de fases intermediárias do tipo $\mathrm{Co}_{3} \mathrm{~W}_{3} \mathrm{C}$ e $\gamma$. Estas fases formadas são indesejáveis por serem fases frágeis e prejudiciais às propriedades mecânicas do metal duro. Além disso, estas fases inibem a diminuição do tamanho de grão de WC na estrutura do carbeto. Os picos observados são em sua maioria as fases $\mathrm{WC}$ e $\mathrm{Co}_{3} \mathrm{~W}_{3} \mathrm{C}$, sendo relacionados à fase $\gamma$ apenas uma pequena quantidade.

O aparecimento destas fases durante a sinterização está de acordo com o diagrama binário de WCCo [13]. É possível que estas fases possam estar relacionadas com a sensibilidade do WC à perda de carbono como conseqüência de sua baixa energia de formação, com a atmosfera de sinterização com característica oxidante, ou com a presença, nos pós, de partida de compostos que reagem com o carbeto, consumindo o 
carbono. É importante destacar que, a fase $\gamma$ foi assim denominada por não ter sido possível uma identificação mais precisa da mesma, o que leva a considerar que ela pode ser o indício da presença de uma fase do tipo carbeto- $\varepsilon$ envolvendo WC e Co (região deficiente de carbono).

Nas Figuras 2-5 são apresentados os difratogramas de raios $\mathrm{X}$ das amostras dopadas com óxido de lantânio $\left(\mathrm{La}_{2} \mathrm{O}_{3}\right)$, sendo que $\mathrm{Am} 1\left(0,5 \% \mathrm{La}_{2} \mathrm{O}_{3}\right)$, Am2 (1,0\% $\left.\% \mathrm{La}_{2} \mathrm{O}_{3}\right)$, Am3 (1,5\% \%a $\left.\mathrm{O}_{3}\right)$ e Am4 (2,0 \% $\left.\mathrm{La}_{2} \mathrm{O}_{3}\right)$. Nas Figuras 6-9 são apresentados os difratogramas de raios $\mathrm{X}$ das amostras dopadas com óxido de cério $\left(\mathrm{CeO}_{2}\right)$, sendo que Am5 (0,5\% $\left.\mathrm{CeO}_{2}\right)$, Am6 (1,0\% $\left.\mathrm{CeO}_{2}\right)$, Am7 (1,5\% $\left.\mathrm{CeO}_{2}\right)$ e Am8 $(2,0 \%$ $\mathrm{CeO}_{2}$ ). As Figuras 10-13 apresentam os difratogramas de raios $\mathrm{X}$ das amostras dopadas com óxido de ítrio $\left(\mathrm{Y}_{2} \mathrm{O}_{3}\right)$, sendo que $\mathrm{Am} 9\left(0,5 \% \mathrm{Y}_{2} \mathrm{O}_{3}\right)$, Am10 (1,0\% $\left.\mathrm{Y}_{2} \mathrm{O}_{3}\right), \operatorname{Am} 11\left(1,5 \% \mathrm{Y}_{2} \mathrm{O}_{3}\right)$ e $\mathrm{Am} 12\left(2,0 \% \mathrm{Y}_{2} \mathrm{O}_{3}\right)$. Pode-se observar que as amostras sinterizadas contendo elementos de terras-raras apresentaram as mesmas fases (WC, СозW3 $\mathrm{C}$ e $\gamma$ ) identificadas na amostra isenta de terra-rara (Figura 1). Isto mostra que a formação destas fases não está, provavelmente, associada ao conteúdo dos elementos de terras-raras incorporados nas amostras estudadas. No entanto, os difratogramas de raios X (Figuras 2-13) mostram pequenas, mais importantes diferenças relacionadas aos picos de difração destas fases. Verifica-se que a concentração de

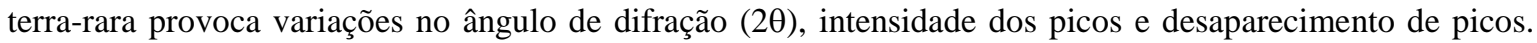
Estas variações é um indicativo de que a adição de terra-rara influencia as propriedades finais de carbeto cementado. De fato, trabalhos reportados na literatura [14-16] indicam que elementos de terras-raras melhoram a condição de molhamento do cobalto e retardamento da transformação $\alpha$-Co (CFC) $\rightarrow \varepsilon$-Co (HC) com concomitante aumento de densificação, resistência mecânica e tenacidade à fratura.

Diante do exposto, as possíveis razões para a oxidação das amostras podem ter sido o método de preparação da mistura dos pós no qual foi utilizado álcool etílico hidratado visando melhorar a etapa de compactação ou o material da cápsula (calcita - $\mathrm{CaCO}_{3}$, que se transforma em aragonita sob ação de HPHT) que podem ter reagido com as amostras durante a sinterização originando as fases intermediárias e/ou fragilizantes.

Outro aspecto importante é que, a sinterização HPHT por ser rápida pode levar o carbono a reagir com o oxigênio adsorvido também de forma rápida resultando na diminuição ou perda de carbono do WC. A conseqüência disto é que não havendo uma boa dissolução do carbono livre na fase líquida novas fases podem surgir por difusão. Quando analisado o trabalho de Gomes [10] em que foi realizada sinterização convencional nas amostras a $1400^{\circ} \mathrm{C}$ por $1 \mathrm{~h}$, observou-se a formação das mesmas fases com concentrações e intensidade de picos bem maiores. Assim, a sinterização convencional promove uma oxidação mais intensa do material e uma maior difusão do Co líquido, o qual se solubiliza no WC formando novas fases.
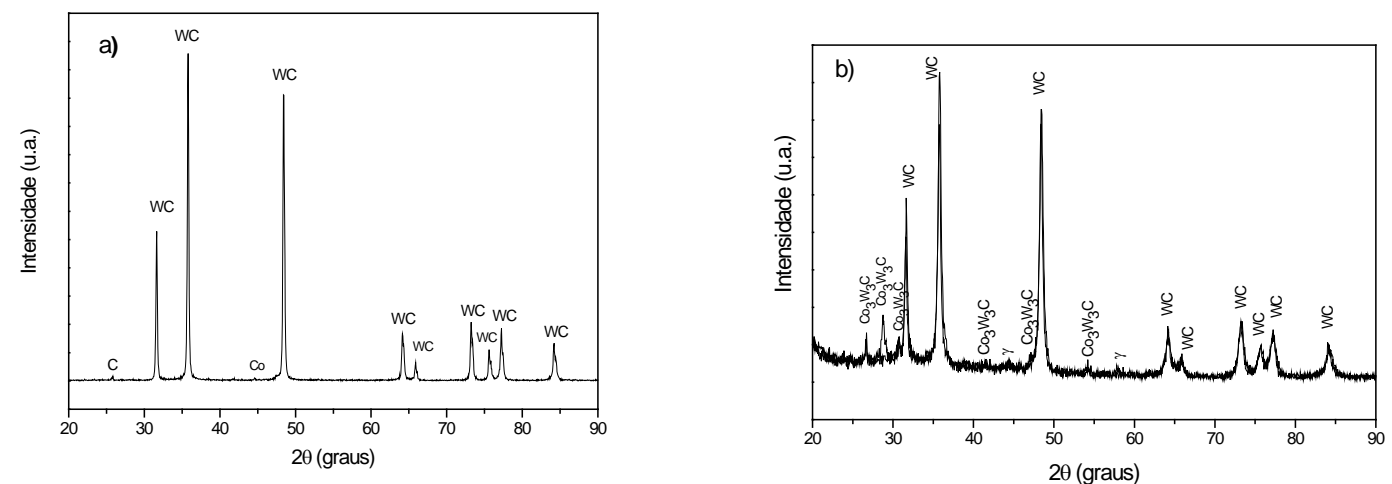

Figura 1: Difratogramas de raios X da amostra Am0 (WC-10Co): (a) antes da sinterização e (b) após sinterização sob condições de alta pressão e alta temperatura. 

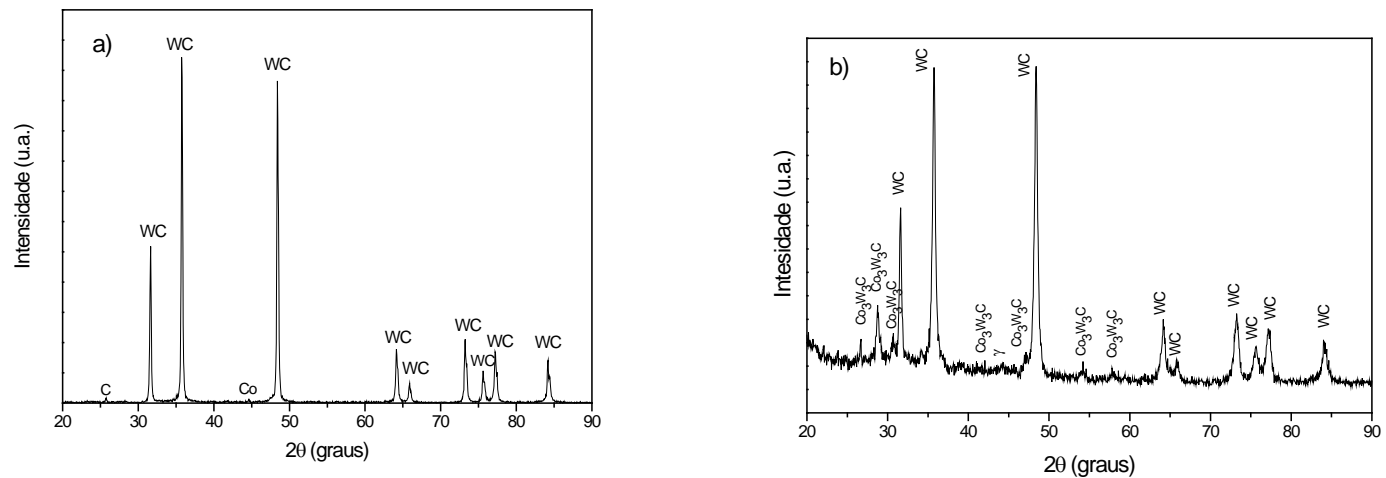

Figura 2: Difratogramas de raios $\mathrm{X}$ da amostra $\mathrm{Am} 1$ (WC-10Co-0,5 $\mathrm{La}_{2} \mathrm{O}_{3}$ ): (a) antes da sinterização e (b) após sinterização sob condições de alta pressão e alta temperatura.
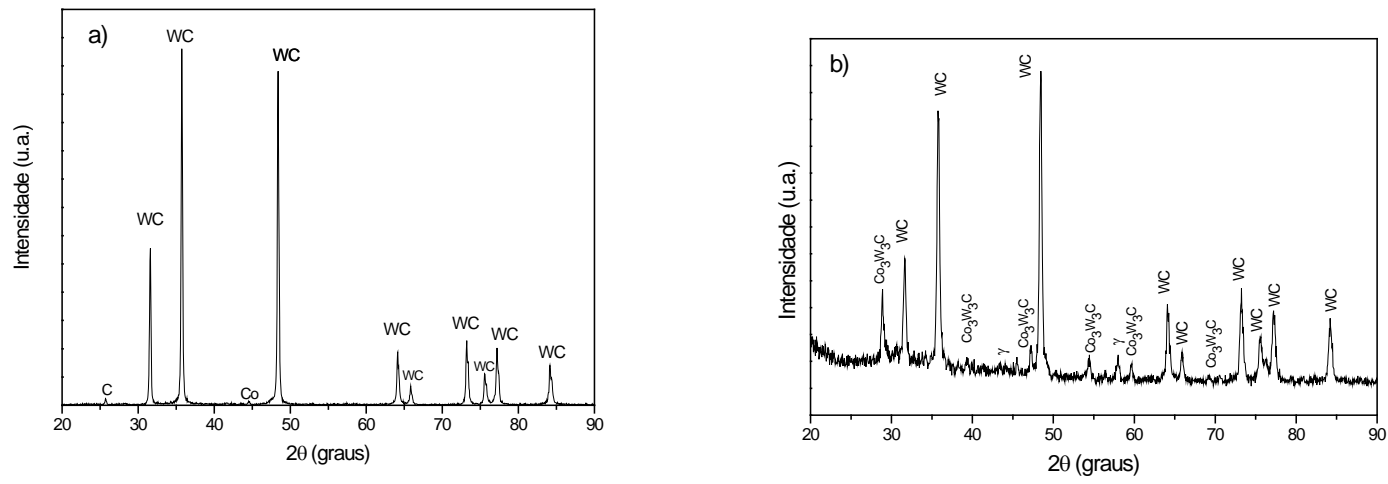

Figura 3: Difratogramas de raios $\mathrm{X}$ da amostra Am2 (WC-10Co- $1 \mathrm{La}_{2} \mathrm{O}_{3}$ ): (a) antes da sinterização e (b) após sinterização sob condições de alta pressão e alta temperatura.
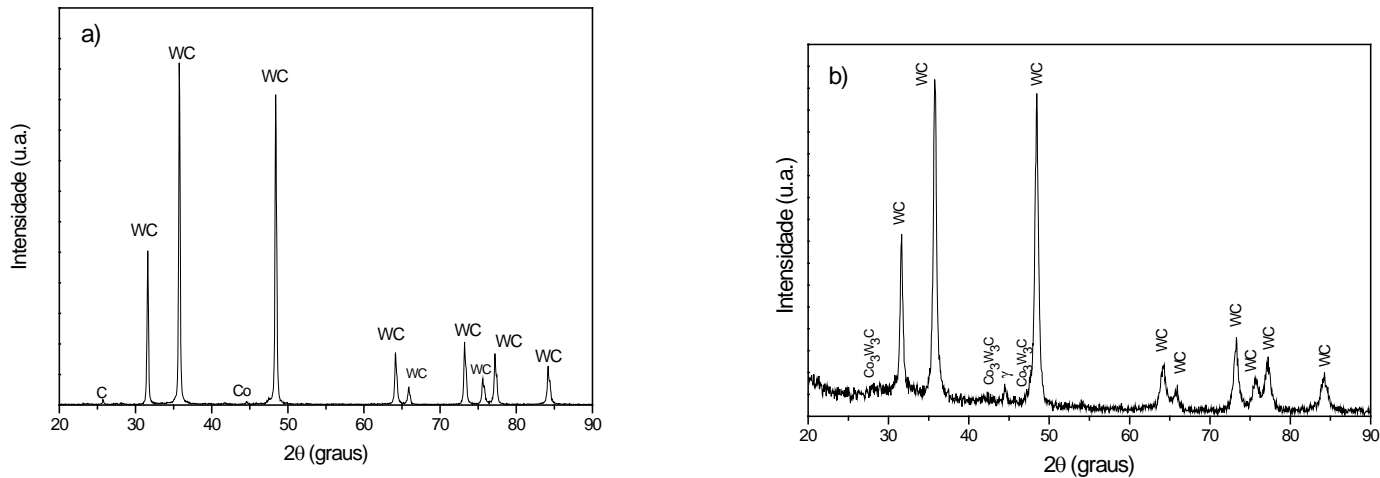

Figura 4: Difratogramas de raios $\mathrm{X}$ da amostra $\mathrm{Am3}$ (WC-10Co-1,5 $\mathrm{La}_{2} \mathrm{O}_{3}$ ): (a) antes da sinterização e (b) após sinterização sob condições de alta pressão e alta temperatura. 

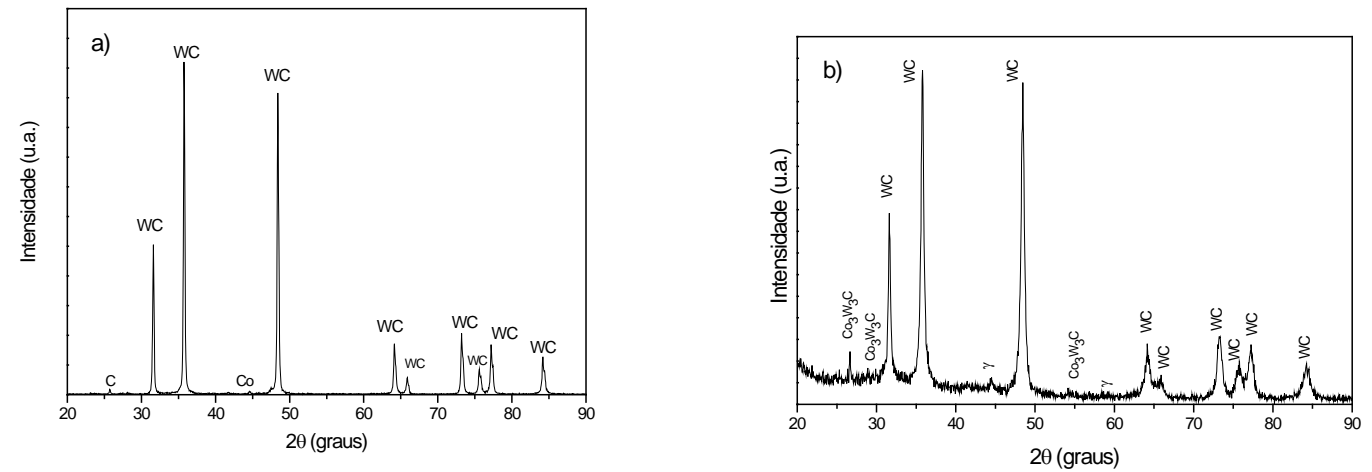

Figura 5: Difratogramas de raios $\mathrm{X}$ da amostra Am4 (WC-10Co- $2 \mathrm{La}_{2} \mathrm{O}_{3}$ ): (a) antes da sinterização e (b) após sinterização sob condições de alta pressão e alta temperatura.
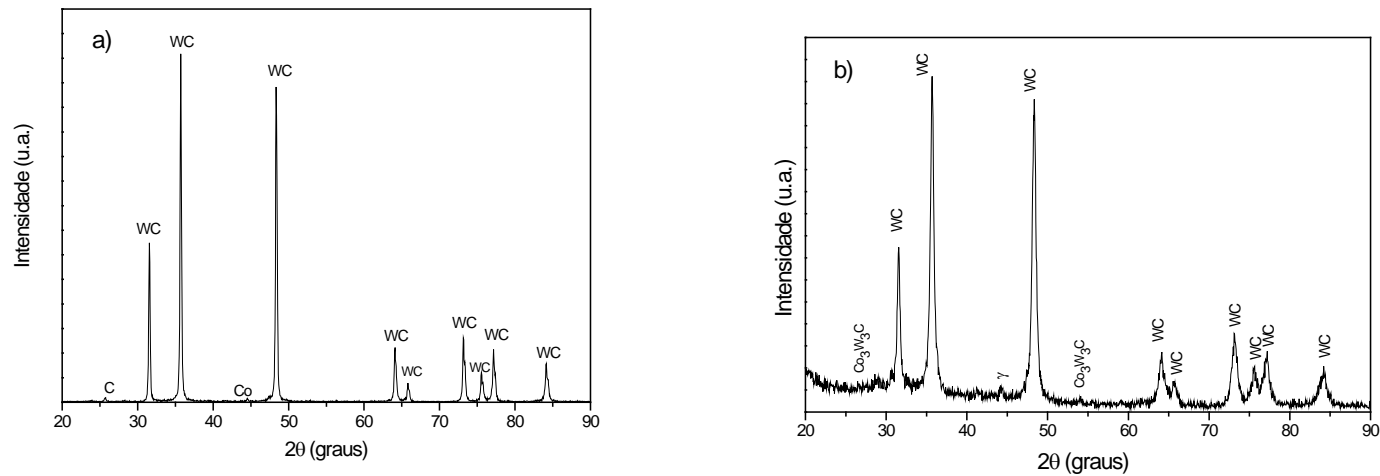

Figura 6: Difratogramas de raios $X$ da amostra Am5 (WC-10Co- $0,5 \mathrm{CeO}_{2}$ ): (a) antes da sinterização e (b) após sinterização sob condições de alta pressão e alta temperatura.
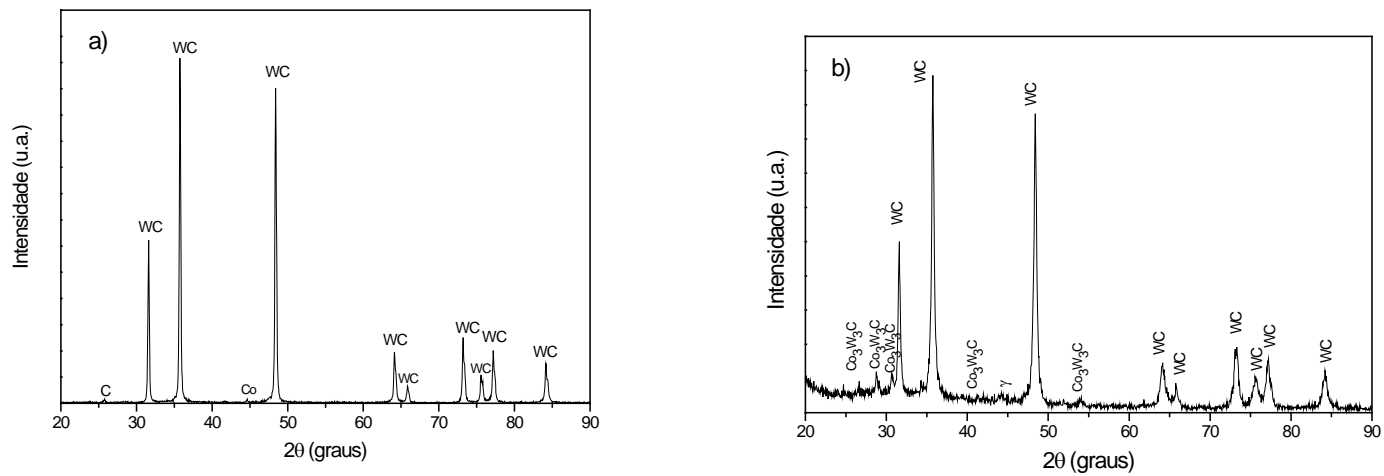

Figura 7: Difratogramas de raios X da amostra Am6 (WC-10Co-1CeO $)_{2}$ : (a) antes da sinterização e (b) após sinterização sob condições de alta pressão e alta temperatura. 

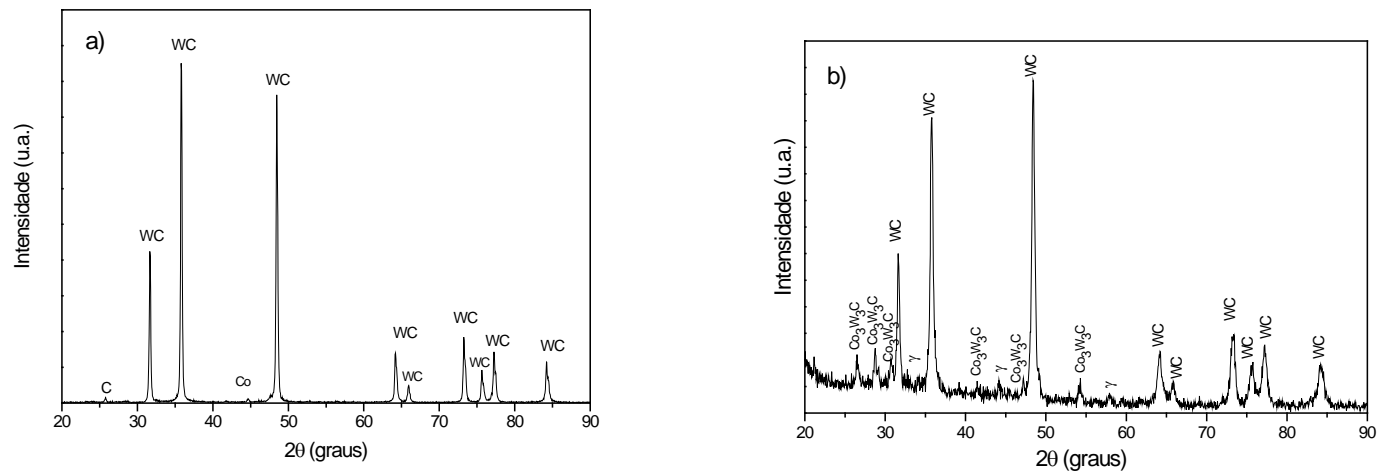

Figura 8: Difratogramas de raios $\mathrm{X}$ da amostra Am7 (WC-10Co-1,5CeO ${ }_{2}$ ): (a) antes da sinterização e (b) após sinterização sob condições de alta pressão e alta temperatura.
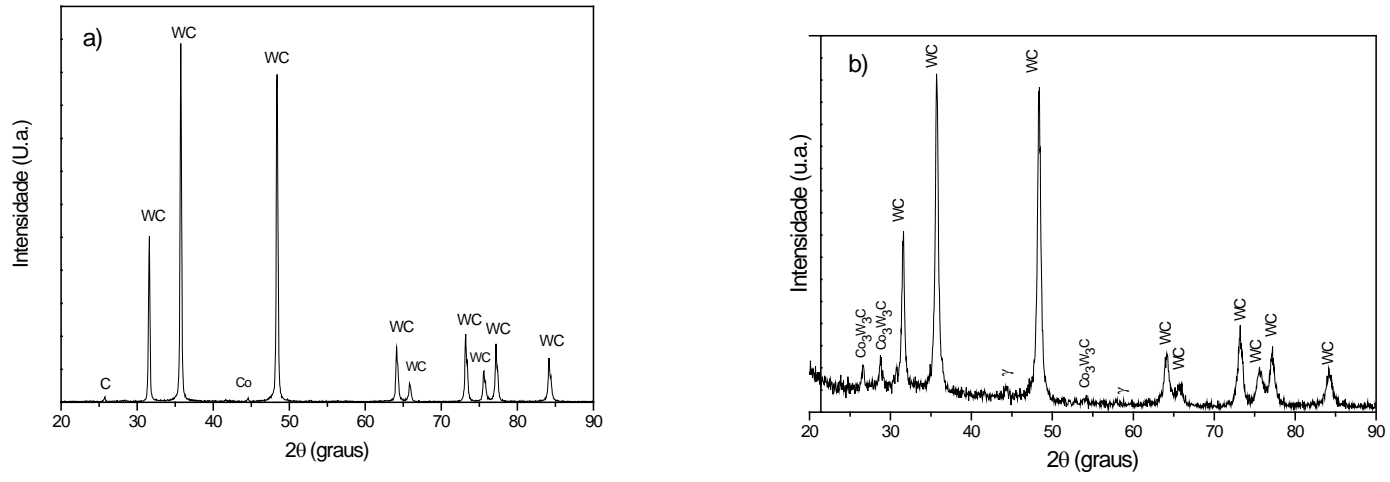

Figura 9: Difratogramas de raios $X$ da amostra $\mathrm{Am} 8$ (WC-10Co-2CeO 2 ): (a) antes da sinterização e (b) após sinterização sob condições de alta pressão e alta temperatura
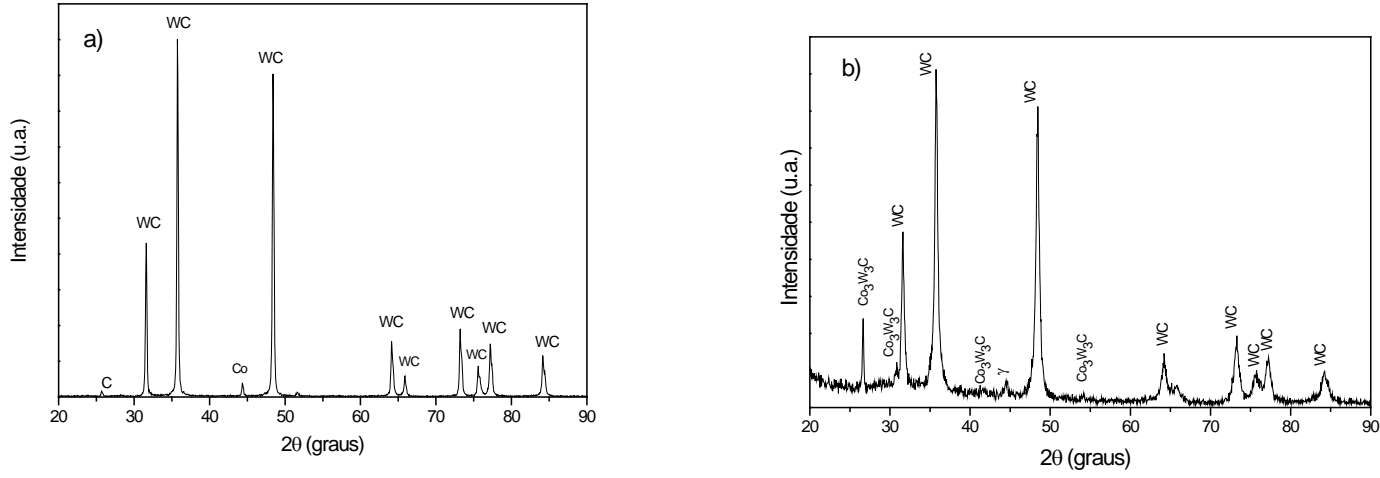

Figura 10: Difratogramas de raios $X$ da amostra Am9 (WC-10Co- $0,5 \mathrm{Y}_{2} \mathrm{O}_{3}$ ): (a) antes da sinterização e (b) após sinterização sob condições de alta pressão e alta temperatura. 

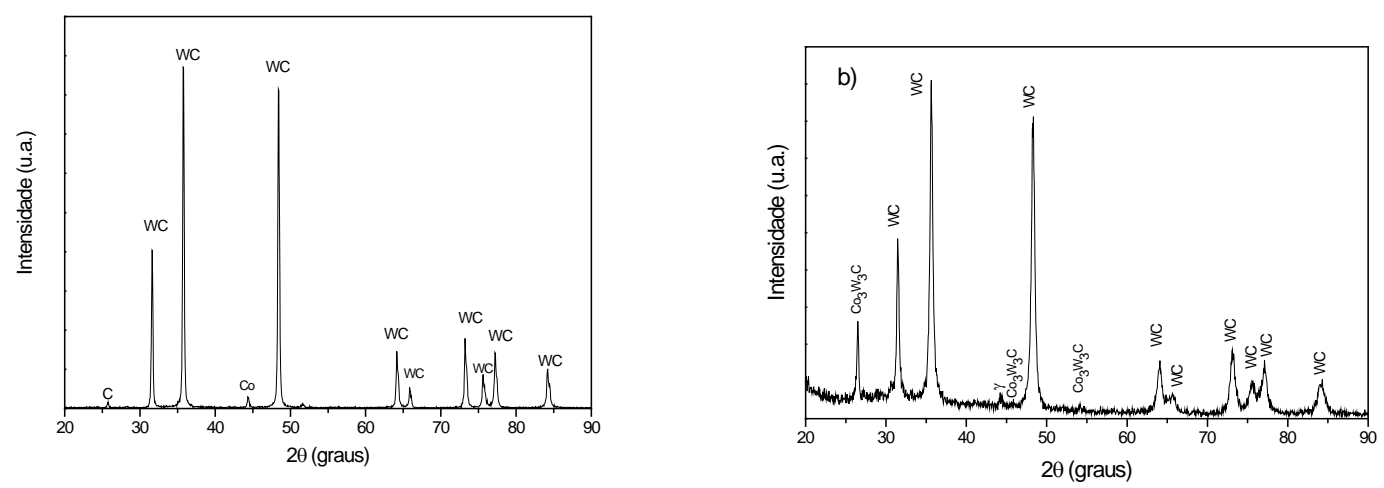

Figura 11: Difratogramas de raios $\mathrm{X}$ da amostra Am10 (WC-10Co- $1 \mathrm{Y}_{2} \mathrm{O}_{3}$ ): (a) antes da sinterização e (b) após sinterização sob condições de alta pressão e alta temperatura.
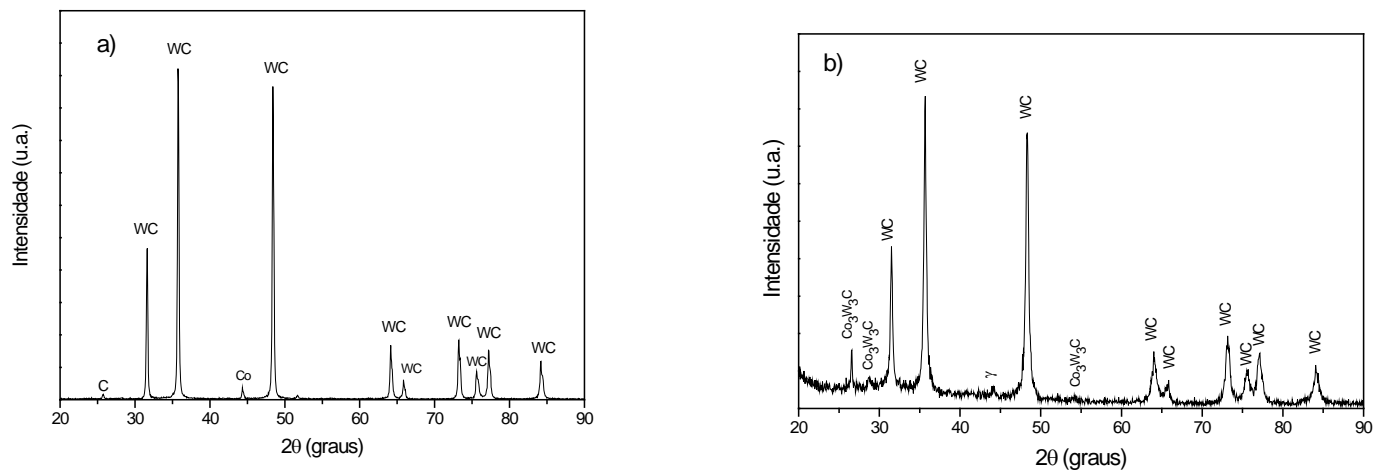

Figura 12: Difratogramas de raios $X$ da amostra Am11 (WC-10Co-1,5 $\mathrm{Y}_{2} \mathrm{O}_{3}$ ): (a) antes da sinterização e (b) após sinterização sob condições de alta pressão e alta temperatura.
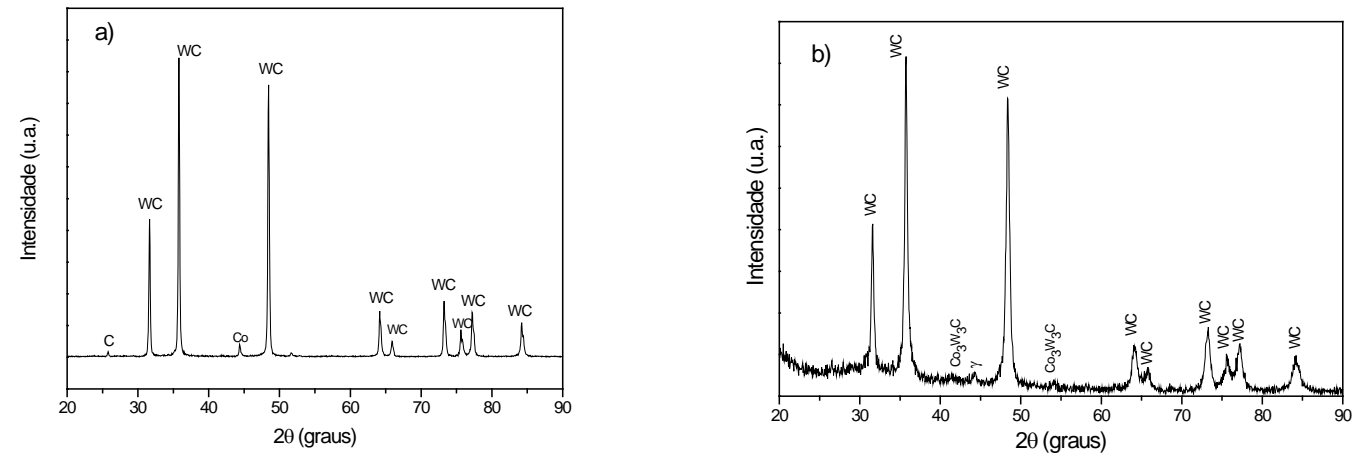

Figura 13: Difratogramas de raios $X$ da amostra Am12 (WC-10Co- $2 \mathrm{Y}_{2} \mathrm{O}_{3}$ ): (a) antes da sinterização e (b) após sinterização sob condições de alta pressão e alta temperatura.

\section{CONCLUSÕES}

Os resultados da análise por difração de raios $\mathrm{X}$ das amostras de carbeto cementado do tipo WC-10Co dopado com diferentes elementos de terras-raras $\left(\mathrm{La}_{2} \mathrm{O}_{3}, \mathrm{CeO}_{2} \mathrm{e} \mathrm{Y}_{2} \mathrm{O}_{3}\right)$ indicou para todas as amostras sinterizadas sob condições de alta pressão e alta temperatura as seguintes fases cristalinas: $\mathrm{WC} \mathrm{Co}_{3} \mathrm{~W}_{3} \mathrm{C}$ e $\gamma$ (carbeto misto de $\mathrm{Co}$ e $\mathrm{W}$ - tipo $\varepsilon$ ). Isto demonstra que a incorporação dos elementos de terras-raras estudados não influenciou a evolução das fases cristalinas do carbeto cementado sinterizado. Verifica-se 
ainda que a adição de terra-rara provocou pequenas diferenças nas intensidades dos picos de difração,

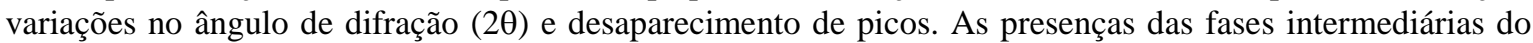
tipo $\mathrm{Co}_{3} \mathrm{~W}_{3} \mathrm{C}$ e $\gamma$ estão fundamentalmente relacionadas à perda de carbono durante a sinterização do WC10Co sob condições de alta pressão e alta temperatura (HPHT). É possível que o método de preparação da mistura, o material da cápsula em contato direto com a amostra ou ainda o curto tempo de sinterização tenha propiciado o surgimento de outras fases.

\section{AGRADECIMENTOS}

Os autores agradecem ao CNPq e FAPERJ pelo apoio financeiro.

\section{BIBLIOGRAFIA}

[1] THÜMMLER, F., OBERACHER, R., “Introduction to powder metallurgy”, Series Editors I. JENKINS and J. V. WOOD - The Institute of Materials, British Library Cataloguing, 1993.

[2] WHITE, C., Handbook of powder metal technologies and applications, APMI International, v. 7, pp. 3-7, 1998.

[3] FANG, Z.Z., WANG, X., RYU, T., et al., "Synthesis, sintering, and mechanical properties of nanocrystalline cemented tungsten carbide - A Review”, International Journal of Refractory Metals and Hard Materials, v. 27, n. 2, pp. 288-299, 2009.

[4] WEI, C., SONG, X., ZAO, S., et al., "In situ synthesis of WC-Co composite powder and densification by sinter-HIP”, International Journal of Refractory Metals and Hard Materials, v. 28, n. 5, pp. 567-571, 2010.

[5] WEL., C.B., SONG, X.Y., FU, J., "Microstructure and properties of ultrafine cemented carbides differences in spark plasma sintering and sinter-HIP”, Materials Science and Engineering A, v. 552, pp. 427433, 2012.

[6] PANOV, V.S., TCHUVILIN, A.M., FALHKOVSKII, V.A., Tecnologia e propriedades de metal duro, Ed. MISIS, Moscou, pp. 464, 2004. (em Russo).

[7] FARIA JR, R.T., RODRIGUES, M.F., ESQUEF, I.A., et al. "On the thermal characterization of a HPHT sintered WC-15wt\% Co hardmetal alloy”, International Journal of Refractory Metals and Hard Materials, v. 23, n. 2, pp. 115-118, 2005.

[8] RODRIGUES, M.F., BOBROVNITCHII, G.S., QUINTANILHA, R., et al., "Sinterização da liga WC/10Co por altas pressões”, Revista Matéria, v. 11, n. 3, pp. 174 - 180, 2006.

[9] XU, C., AI, X., HUANG, C., “Research and development of rare-earth cemented carbides”, International Journal of Refractory Metals and Hard Materials, v. 19, pp. 159-168, 2001.

[10] GOMES, C.M.F., Estudo da influência da adição de terras-raras na sinterização e propriedades mecânicas de carbeto cementado, M.Sc., UENF-PPGECM, Campos dos Goytacazes, RJ, Brasil, 2004.

[11] SHA, L., “Study on rare-earth doped cemented carbides in China”, International Journal of Refractory Metals and Hard Materials, v. 27, pp. 528-534, 2009.

[12] BOBROVNITCHII, G.S., SKURY, A.L.D., MONTEIRO, S.N., "Effect of the high pressure and temperature cycling in the sintering of cubic boron nitride composites under HPHT conditions”, Materials Science Forum, v. 660-661, pp. 837-843, 2010.

[13] MCHALE, A.E., "Phase equilibrium diagrams - phase diagrams for ceramists”, v. 10, Fig. 8969, The American Ceramic Society, Westerville, Ohio, 1994.

[14] YAO, X., HUANG, P., LU, H., “Effects of rare-earth oxide on the martensite transformation of cobalt and mechanical properties of cemented carbides”, Powder Metallurgy Technology, v. 5, pp. 200-204, 1987.

[15] LUO, Z., "Research on effect of rare-earth elements on properties of cemented carbides”, Cemented Carbide, v. 8, pp. 12-19, 1991.

[16] PAN, Q., “Effects of rare-earth oxide on the properties of WC-Co cemented carbide”, Rare Metals and Materials Engineering, v. 22, pp. 35-38, 1993. 